\title{
Symptoms and lung function decline in a middle- aged cohort of males and females in Australia
}

\author{
This article was published in the following Dove Press journal: \\ International Journal of COPD \\ 26 May 2016 \\ Number of times this article has been viewed
}

\author{
Michael J Abramson' \\ Sonia Kaushik' \\ Geza P Benke' \\ Brigitte M Borg ${ }^{2}$ \\ Catherine L Smith' \\ Shyamali C Dharmage ${ }^{3}$ \\ Bruce R Thompson ${ }^{2}$ \\ 'Department of Epidemiology \& \\ Preventive Medicine, School of \\ Public Health \& Preventive Medicine, \\ Monash University, ${ }^{2}$ Department of \\ Allergy, Immunology \& Respiratory \\ Medicine, The Alfred Hospital, ${ }^{3}$ Centre \\ for Epidemiology and Biostatistics, \\ Melbourne School of Population \\ and Global Health, University of \\ Melbourne, Melbourne, Victoria, \\ Australia
}

Correspondence: Michael J Abramson School of Public Health \& Preventive Medicine, Monash University, The Alfred Centre, 99 Commercial Rd, Melbourne, Victoria 3004, Australia

Tel +6I 399030573

Fax +6I 399030556

Email michael.abramson@monash.edu
Background: The European Community Respiratory Health Survey is a major international study designed to assess lung health in adults. This Australian follow-up investigated changes in symptoms between sexes and the roles of asthma, smoking, age, sex, height, and change in body mass index $(\triangle \mathrm{BMI})$ on lung function decline (LFD), which is a major risk factor for chronic obstructive pulmonary disease (COPD).

Methods: LFD was measured as the rate of decline over time in $\mathrm{FEV}_{1}(\mathrm{~mL} /$ year $)\left(\Delta \mathrm{FEV}_{1}\right)$ and FVC ( $\triangle F V C)$ between 1993 and 2013. Multiple linear regression was used to estimate associations between risk factors and LFD, separately for males and females. Multiple logistic regression was used to assess sex differences and changes in respiratory symptoms over time.

Results: In Melbourne, 318 subjects (53.8\% females) participated. The prevalence of most respiratory symptoms had either remained relatively stable over 20 years or decreased (significantly so for wheeze). The exception was shortness of breath after activity, which had increased. Among the 262 subjects who completed spirometry, current smoking declined from $20.2 \%$ to $7.3 \%$. Overall mean ( \pm standard deviation) $\mathrm{FEV}_{1}$ declined by $23.1( \pm 17.1)$ and FVC by 22.9 $( \pm 20.2) \mathrm{mL} /$ year. Predictors of $\triangle \mathrm{FEV}_{1}$ in males were age, maternal smoking, and baseline $\mathrm{FEV}_{1}$; and in females they were age, $\triangle \mathrm{BMI}$, baseline $\mathrm{FEV}_{1}$, and pack-years in current smokers. Decline in FVC was predicted by baseline FVC, age, and $\triangle \mathrm{BMI}$ in both sexes; however, baseline FVC predicted steeper decline in females than males.

Conclusion: Most respiratory symptoms remained stable or decreased over time in both sexes. Age, baseline lung function, and change in BMI were associated with the rate of decline in both sexes. However, obesity and personal smoking appear to put females at higher risk of LFD than males. Health promotion campaigns should particularly target females to prevent COPD.

Keywords: cohort study, lung function, body mass index, tobacco smoking, COPD, respiratory symptoms

\section{Introduction}

The European Community Respiratory Health Survey (ECRHS) is a major international study designed to assess lung health in adults. Findings from the first ECRHS showed that prevalence of asthma and allergies as assessed by serum Immunoglobulin E (IgE) were higher in Australia and New Zealand than most European countries. ${ }^{1,2}$ In our Melbourne center, the major risk factors for current asthma in young adults were being a female, maternal asthma, smoking, nasal allergies, early respiratory infection, occupational exposures, and atopy. ${ }^{3}$ A follow-up of 5,002 subjects without asthma from 12 centers found that chronic cough and phlegm was an independent predictor of incident chronic obstructive pulmonary disease (COPD), as defined by prebronchodilator spirometry. ${ }^{4}$

Studies on lung health in adults typically assess both respiratory symptoms and lung function cross-sectionally. Longitudinal follow-up of respiratory symptoms has 
mostly been conducted in occupational cohorts. A 10-year follow-up of a population-based cohort of adults in rural Canada found that cough, phlegm, and wheeze increased significantly over time. ${ }^{5}$ The Busselton Population Health study in Western Australia found that doctor-diagnosed asthma increased over 16 years accompanied by increased reporting of cough and phlegm, but not wheeze. ${ }^{6}$ The incidence of asthma and respiratory symptoms in adults was related to maternal smoking in Norway, ${ }^{7}$ but only weakly to air pollution in several European centers. ${ }^{8}$

Lung function has been measured by spirometry in the ECRHS and many other epidemiological studies in adults. It is well known that a high proportion of the cross-sectional variance in lung function is explained by age, sex, height, and ethnicity. ${ }^{9,10}$ There are many other risk factors for longitudinal lung function decline (LFD), including tobacco smoking, ${ }^{11}$ occupational exposures, ${ }^{12,13}$ asthma, ${ }^{14,15}$ and allergies. ${ }^{16}$ Although obesity is associated with adult-onset asthma $^{17}$ and restrictive ventilatory defects, the effect on LFD is uncertain. ${ }^{18}$ Furthermore, the relative contributions of these factors to LFD remains a subject of debate and there are knowledge gaps in this area. Excessively rapid LFD is a well-established precursor of COPD,${ }^{11}$ airway and systemic inflammation, ${ }^{19}$ hospitalization, and death from COPD. ${ }^{20}$

Therefore, we investigated the role of these potential risk factors including increase in body mass index $(\triangle \mathrm{BMI})$ on LFD using ECRHS data collected on two different occasions from the Melbourne cohort. We specifically asked the following questions:

- Do changes in symptoms and history of respiratory conditions differ between males and females over 20 years?

- What are the risk factors for LFD in males and females?

\section{Methods}

\section{Subjects}

The ECRHS was a multicenter international cohort study of asthma, potential risk factors, and treatment for the disease (www.ecrhs.org). The Melbourne center participated in both ECRHS I (November 1992 to April 1994, hereafter referred to as 1993) and ECRHS III (November 2012 to January 2014, referred to as 2013). The sampling strategy has been fully described elsewhere. ${ }^{21}$

Briefly, for ECRHS I, a random sample of 4,500 adults aged 20-44 years was selected from electoral rolls in Melbourne, Australia. Postal questionnaires were returned by 3,200 subjects. ${ }^{22}$ Subsequently, a sample of 2,042 subjects (including 433 individuals from a symptomatic sample, who reported symptoms suggesting asthma) was invited to complete a comprehensive interviewer-administered main questionnaire and lung function tests. The 876 participants who attended the first survey were reinvited for ECRHS III when 318 completed additional questionnaires and 262 lung function tests. The study was approved by the Human Research Ethics Committees of Monash University and the Alfred Hospital. All participants provided written informed consent.

\section{Questionnaire}

The main questionnaire included validated questions about wheeze, shortness of breath after activity, nocturnal cough, morning sputum, nasal allergies including hay fever, eczema or skin allergies, and cigarette smoking. ${ }^{23,24}$ Current asthma was defined as asthma ever confirmed by a doctor and any of the following in the previous 12 months: at least one asthma symptom (wheezing; waking up with chest tightness; shortness of breath at rest during the day, following strenuous activity, or during the night), an asthma attack, or use of an inhaled or oral medication to help breathing. ${ }^{25}$

\section{Measurements}

BMI was calculated as weight $(\mathrm{kg}) /$ height $(\mathrm{m})^{2}$. Spirometry was performed using a computerized Fleisch pneumotach (Hewlett Packard, Palo Alto, CA, USA) in 1993 and an EasyOne spirometer (NDD, Zürich CH, Switzerland) in 2013. The current spirometry guidelines at the time were followed. ${ }^{26,27}$ Baseline lung function was compared with Caucasian predicted values from the US National Health And Nutrition Examination Survey. ${ }^{9}$ The rate of LFD was measured as declines in $\mathrm{FEV}_{1}\left(\mathrm{~mL} /\right.$ year) $\left(\Delta \mathrm{FEV}_{1}\right)$ and FVC $(\Delta \mathrm{FVC})$ divided by the time interval (in years) between tests in 262 subjects who attended both the surveys in Melbourne.

\section{Statistical analysis}

We compared the prevalences of respiratory symptoms, asthma, and allergies between males and females and between ECRHS I and III using logistic regression with robust errors estimated from generalized estimating equations. Sex, survey time (categorical), and an interaction between them were included as predictors in the model. Multiple linear regression was used to estimate associations between risk factors and rate of LFD separately for males and females. The following covariates were considered: height, current smoking, pack-years in 2013, maternal smoking, asthma, inhaled or oral medication in 1993, and $\triangle B M I$. The stepwise algorithm entered a covariate into the model if $P<0.05$ and removed it if $P>0.1$. At each step, all eligible variables were considered 
Table I The number (\%) of participants with respiratory symptoms or allergies by sex and survey

\begin{tabular}{|c|c|c|c|c|c|c|c|}
\hline \multirow{2}{*}{$\begin{array}{l}\text { Respiratory } \\
\text { symptom or } \\
\text { allergy }\end{array}$} & \multicolumn{2}{|c|}{ Males $(n=\mid 47)$} & \multicolumn{2}{|c|}{ Females $(n=|7|)$} & \multirow{2}{*}{$\begin{array}{l}\text {-value } \\
\text { comparing } \\
\text { surveys }^{\mathrm{a}}\end{array}$} & \multirow{2}{*}{$\begin{array}{l}P \text {-value } \\
\text { comparing } \\
\text { sex }^{\mathrm{b}}\end{array}$} & \multirow{2}{*}{$\begin{array}{l}P \text {-value for } \\
\text { sex } \times \text { time } \\
\text { interaction }\end{array}$} \\
\hline & 1993 & 2013 & 1993 & 2013 & & & \\
\hline Wheeze & $53(36 \%)$ & $39(27 \%)$ & 75 (44\%) & $46(27 \%)$ & $<0.001$ & 0.385 & 0.250 \\
\hline SOB after activity & 45 (3।\%) & $59(40 \%)$ & $64(37 \%)$ & 73 (43\%) & 0.018 & 0.262 & 0.504 \\
\hline Nocturnal cough & 39 (27\%) & $38(26 \%)$ & 70 (4I\%) & $58(34 \%)$ & 0.289 & 0.006 & 0.405 \\
\hline Morning sputum & $24(16 \%)$ & $17(12 \%)$ & $11(6 \%)$ & II (7\%) & 0.405 & 0.008 & 0.385 \\
\hline Nasal allergies & $64(44 \%)$ & $74(50 \%)$ & 91 (53\%) & $95(56 \%)$ & 0.061 & 0.132 & 0.408 \\
\hline Skin allergies & $66(45 \%)$ & $53(36 \%)$ & 92 (54\%) & $78(46 \%)$ & 0.004 & 0.049 & 0.814 \\
\hline Current asthma & $32(22 \%)$ & $36(24 \%)$ & $42(25 \%)$ & $48(28 \%)$ & 0.105 & 0.474 & 0.881 \\
\hline
\end{tabular}

Notes: a ${ }^{P}$-value calculated from logistic regression (with GEEs) - marginal effect of time, ${ }^{b}$-value calculated from logistic regression (with GEEs) - marginal effect of sex, and cP-value calculated from logistic regression (with GEEs) interaction for sex $\times$ time.

Abbreviations: GEE, generalized estimating equations; SOB, shortness of breath.

for removal and entry. Results are presented for the most parsimonious models as regression coefficients with $95 \%$ confidence intervals. Statistical analyses were conducted in SPSS (version 20, IBM Corp, Armonk, NY, USA) or Stata version 14 (Stata Corporation, College Station, TX, USA).

\section{Results}

\section{Symptoms and allergies}

The prevalence (and 95\% confidence intervals) of respiratory symptoms and allergies by sex over time are shown in Table 1 for 318 participants who completed questionnaires on two occasions. There was no evidence that the effect of time on symptom prevalence differed by sex (no interactions were statistically significant). In both surveys, nocturnal cough $(P=0.006)$ and skin allergies $(P=0.049)$ were significantly more prevalent in females than males. Conversely, morning sputum was slightly more prevalent in males than females $(P=0.008)$. The prevalence of most symptoms had either remained fairly constant or decreased over 20 years, significantly so for wheeze $(P<0.001)$ and skin allergies $(P=0.004)$. However, prevalence for shortness of breath after activity had increased $(P=0.018)$.

Compared with participants in both surveys, those who only participated in 1993 were slightly younger (33.5 vs 35.5 years, $P<0.001)$ and significantly more likely to report wheeze $(P=0.014)$, nocturnal cough $(P=0.033)$, morning sputum $(P=0.02)$, or nasal allergies $(P=0.049)$. There were no significant differences between those who continued to participate and drop outs in sex, shortness of breath after activity, current asthma, skin allergies, inhaled or oral medications, or smoking in 1993 (data not shown).

\section{Lung function}

The baseline and follow-up characteristics of the 262 subjects who completed spirometry are described by sex in Table 2 . By the time of resurvey in 2013, the subjects were almost
20 years older; had gained, on average, $7-8 \mathrm{~kg}$ in weight; mean BMI had increased by $2.2 \mathrm{~kg} / \mathrm{m}^{2}$ in males and $3.2 \mathrm{~kg} / \mathrm{m}^{2}$ in females. Lung function had declined; overall mean $\mathrm{FEV}_{1}$ declined by $23.1( \pm 17.1)$ and FVC by $22.9( \pm 20.2) \mathrm{mL} / \mathrm{year}$. Mean $\triangle \mathrm{FEV}_{1}$ and $\triangle \mathrm{FVC}$ in males and females are given

Table 2 Baseline and follow-up characteristics of subjects who had spirometry in 1993 and 2013

\begin{tabular}{|c|c|c|}
\hline & $\begin{array}{l}\text { Males } \\
\text { Mean (SD) } \\
(n=130)\end{array}$ & $\begin{array}{l}\text { Females } \\
\text { Mean (SD) } \\
(n=132)\end{array}$ \\
\hline \multicolumn{3}{|c|}{ Baseline characteristics ( 1993) } \\
\hline Age (years) & $35.6(5.9)$ & $35.1(6.4)$ \\
\hline Weight (kg) & $80.3(11.9)$ & $64.8(11.9)^{*}$ \\
\hline BMI $\left(\mathrm{kg} / \mathrm{m}^{2}\right)$ & $25.8(2.8)$ & $24.5(4.1)^{\dagger}$ \\
\hline $\mathrm{FEV}_{1}(\mathrm{~L})$ & $4.02(0.7)$ & $3.0(0.4)^{*}$ \\
\hline (\% predicted) & $94.7(14.0)$ & $97.0(11.5)$ \\
\hline FVC (L) & $5.25(0.77)$ & $3.82(0.66)^{*}$ \\
\hline (\% predicted) & 99.5 ( 11.5$)$ & $102.4(13.1)$ \\
\hline $\mathrm{FEV}_{1} / \mathrm{FVC}(\%)$ & $77(7.2)$ & $79(6.8)^{\ddagger}$ \\
\hline \multicolumn{3}{|l|}{ Smoking status (\%) } \\
\hline Never smoked & 52.3 & 56.1 \\
\hline Former smoker & 26.9 & 24.2 \\
\hline Current smoker & 20.8 & 19.7 \\
\hline \multicolumn{3}{|c|}{ Characteristics on follow-up (2013) } \\
\hline Age (years) & $55.4(5.9)$ & $55.0(6.3)$ \\
\hline Age difference (years) & $19.8(0.59)$ & $19.8(0.58)$ \\
\hline Weight (kg) & $87.4(16.5)$ & $72.9(16.3)^{*}$ \\
\hline Weight difference $(\mathrm{kg})$ & $7.0(9.1)$ & $8.1(9.8)$ \\
\hline BMI $\left(\mathrm{kg} / \mathrm{m}^{2}\right)$ & $27.9(4.4)$ & $27.7(5.9)$ \\
\hline$\Delta B M I$ I993-20I3 (kg/m²) & $2.2(2.97)$ & $3.2(3.8) * *$ \\
\hline $\mathrm{FEV}_{1}(\mathrm{~L})$ & $3.61(0.68)$ & $2.52(0.46)^{*}$ \\
\hline FVC (L) & $4.84(0.8)$ & $3.35(0.6)^{*}$ \\
\hline$\Delta \mathrm{FEV}$, in $\mathrm{mL} /$ year & $21.4(19.4)$ & $24.7(14.4)$ \\
\hline$\Delta \mathrm{FVC}$ in $\mathrm{mL} /$ year & $21.1(20.1)$ & $24.7(20.2)$ \\
\hline $\mathrm{FEV}_{1} / \mathrm{FVC}$ decline (\%) & $2.2(5.0)$ & $3.4(5.4)$ \\
\hline Current smoker (\%) & 6.9 & 7.7 \\
\hline $\begin{array}{l}\text { Pack-years for current } \\
\text { smokers } 2013 \text { median (IQR) }\end{array}$ & I $3.6(\mid 1.0,35.3)$ & $28.4(7.8,33.8)$ \\
\hline
\end{tabular}

Notes: $* P<0.001,{ }^{*} * P=0.014,{ }^{\dagger} P=0.004,{ }^{\ddagger} P=0.006$.

Abbreviations: $\triangle \mathrm{BMI}$, change in body mass index; $\triangle \mathrm{FEV}$, rate of decline over time in forced expiratory volume in I second ( $\mathrm{mL} /$ year); $\triangle \mathrm{FVC}$, rate of decline over time in forced vital capacity (mL/year); IQR, interquartile range; SD, standard deviation. 
Table 3 Multiple regression coefficients (with 95\% Cl) for associations between decline in FEV, and clinical characteristics

\begin{tabular}{lll}
\hline Predictors & Males $(\mathbf{n}=\mathbf{I 3 0})$ & Females $(\mathbf{n}=\mathbf{I 3 2})$ \\
\hline Age (I993) & $\mathrm{I} .2(0.6, \mathrm{I} .7)$ & $0.85(0.5,1.2)$ \\
Baseline FEV & $\mathrm{I} 3.3(8.3,18.3)$ & $10.8(5.7,15.9)$ \\
Maternal smoking & $9.4(2.8,16)$ & $\mathrm{NS}$ \\
Pack-years smoked by 20I3 & $\mathrm{NS}$ & $0.37(0.07,0.67)$ \\
Height (I993) & $-0.8(-1.2,-0.3)$ & $\mathrm{NS}$ \\
$\Delta \mathrm{BMI}$ & $\mathrm{NS}$ & $\mathrm{I} .3(0.7,1.8)$ \\
\hline
\end{tabular}

Note: Other covariates were not included in the final model.

Abbreviations: $\triangle \mathrm{BMI}$, change in body mass index; $\mathrm{Cl}$, confidence interval; NS, not significant, that is, covariate were not entered in final regression model.

in Table 2. The differences between males and females in weight, BMI in 1993, lung function on both occasions, and $\triangle \mathrm{BMI}$ were statistically significant. By 2013, 16 (6.0\%) participants had Global initiative for Obstructive Lung Disease (GOLD) Stage II or greater COPD $\left(\mathrm{FEV}_{1} / \mathrm{FVC}<70 \%\right.$ and $\mathrm{FEV}_{1}<80 \%$ predicted).

\section{Predictors of lung function decline}

Age and baseline $\mathrm{FEV}_{1}$ were associated with the decline in $\mathrm{FEV}_{1}$ in both sexes (Table 3). However, maternal smoking and height were also independent predictors in males. Pack-years smoked and change in BMI were independent predictors in females. Current smoking in 2013, asthma and inhaled or oral medication in 1993 were not related to $\triangle \mathrm{FEV}_{1}$ in either sex. However, mean $\triangle \mathrm{FEV}_{1}$ was significantly more rapid among those who continued smoking $(32.7 \pm 20.9 \mathrm{~mL} /$ year $)$ compared with those who quit between 1993 and 2013 (17.1 $\pm 23.5 \mathrm{~mL} /$ year, $P=0.02$ ). The relationship between baseline smoking status and mean

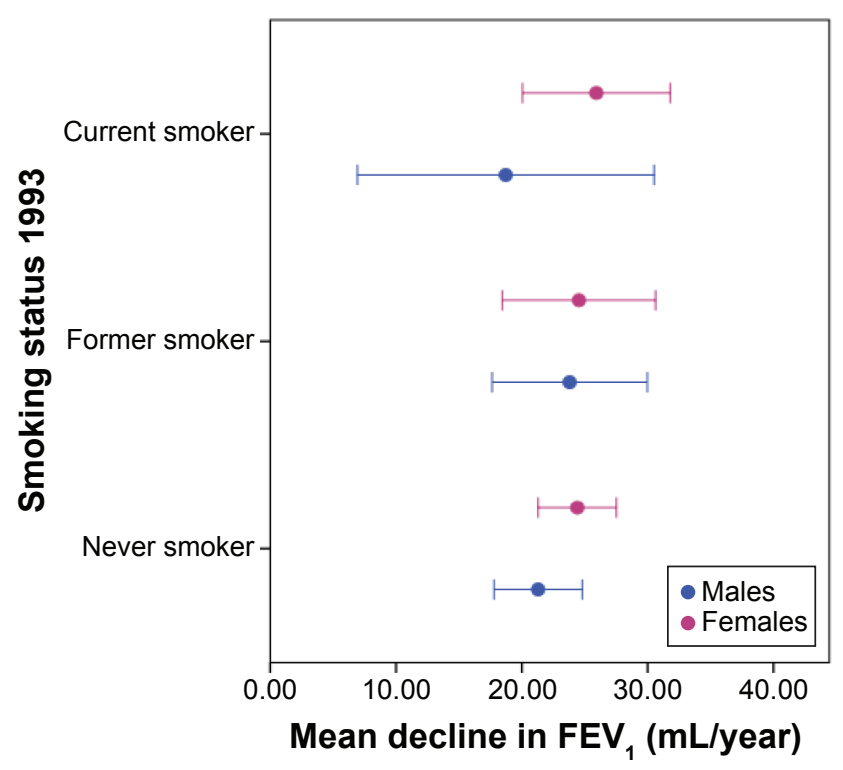

Figure I Mean (with $95 \% \mathrm{Cl}$ ) decline in $\mathrm{FEV}$, $\mathrm{mL} /$ year by smoking at baseline. Abbreviation: $\mathrm{Cl}$, confidence interval.
Table 4 Multiple regression coefficients (with $95 \% \mathrm{Cl}$ ) for associations between decline in FVC and clinical characteristics

\begin{tabular}{lll}
\hline Predictors & Males $(\mathbf{n}=130)$ & Females $(\mathbf{n}=132)$ \\
\hline Age $($ I993) & I.I $(0.6,1.7)$ & $1.4(I .0,1.8)$ \\
Baseline FVC & $10.4(5.2,15.7)$ & $20.4(15.0,25.8)$ \\
Height (I993) & $-0.7(-0.1,-1.3)$ & $-0.6(-0.1,-1.1)$ \\
$\Delta$ BMI & $2.0(0.9,3.1)$ & $1.8(1.0,2.5)$ \\
\hline
\end{tabular}

Note: Other covariates were not included in the final model. Abbreviations: $\triangle \mathrm{BMI}$, change in body mass index; $\mathrm{Cl}$, confidence interval.

$\triangle \mathrm{FEV}_{1}$ is shown in Figure 1. Although $\triangle \mathrm{FEV}_{1}$ was greater in females than males who were smokers in 1993, the confidence intervals were wide and overlapped. Nonetheless, the effect of pack-years smoked by 2013 was greatest in females.

Furthermore, age, baseline FVC, height, and $\triangle \mathrm{BMI}$ were independent predictors of $\triangle \mathrm{FVC}$ in both sexes (Table 4). Smoking in 2013, pack-years smoked, maternal smoking, asthma, inhaled or oral medication in 1993 were not related to $\triangle \mathrm{FVC}$ in either sex. Nor was there any significant difference in $\triangle \mathrm{FVC}$ between those who continued to smoke or quit. The relationship between baseline BMI and mean $\triangle \mathrm{FVC}$ is shown in Figure 2. The effect was greatest in females who were already obese at baseline.

\section{Discussion}

This 20-year follow-up of a cohort of Melbourne adults has found that prevalence of most respiratory symptoms had either remained relatively stable or decreased (significantly so for wheeze). The exception was shortness of breath after activity, which had increased. Shortness of breath is not

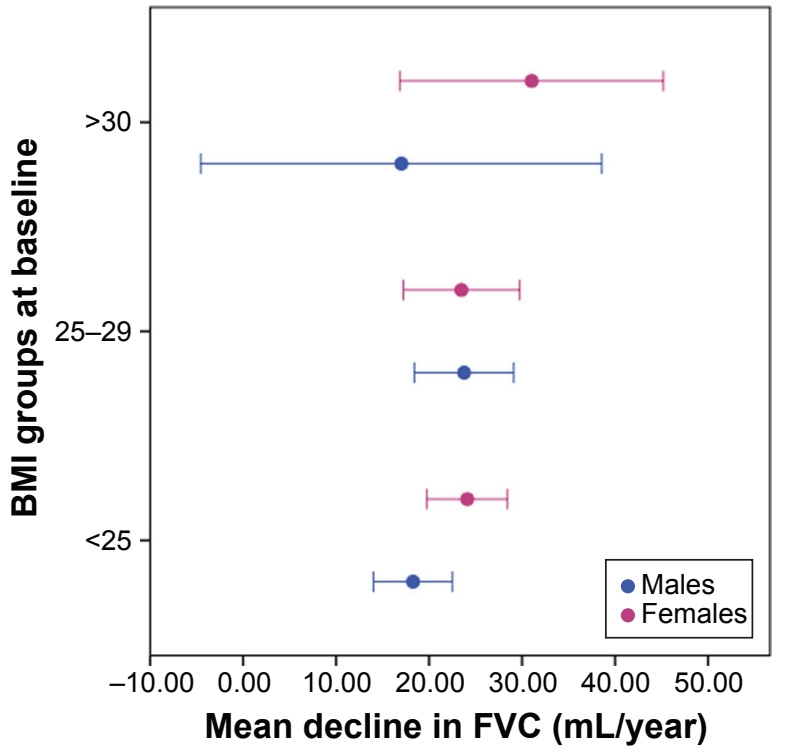

Figure 2 Mean decline in FVC (mL/year) over time categorized by baseline BMI $\left(\mathrm{kg} / \mathrm{m}^{2}\right)$ in males and females.

Abbreviation: BMI, body mass index. 
specific to respiratory disease and may be due to cardiac disease or simply physical deconditioning in this age group. The prevalence of wheeze was comparable, but the prevalence of sputum was less compared with adults of similar age in Busselton, ${ }^{6}$ or rural Canadian adults who were 10 years younger on average. ${ }^{5}$

The rate of LFD (both $\triangle \mathrm{FEV}_{1}$ and $\triangle \mathrm{FVC}$ ) was slightly higher in females than males. Decline in $\mathrm{FEV}_{1}$ was associated with age and baseline $\mathrm{FEV}_{1}$ in both sexes, as well as height and maternal smoking in males, and pack-years and $\triangle \mathrm{BMI}$ in females. Age, baseline lung function, and $\triangle \mathrm{BMI}$ were associated with decline in FVC in both sexes. However, the influence of baseline lung function was not consistent with the "horse-racing effect" in COPD, in which those with the lowest lung function are expected to have the most rapid rate of decline. ${ }^{11,28}$ This might be because we recruited a community-based sample, in which relatively few individuals met spirometric criteria for COPD.

Change in BMI was slightly higher in females compared with males, which could be attributed to hormonal changes during menopause. Although we did not collect data on menopause, the mean age at natural menopause is 48.8 years internationally and $50 \%$ of Australian females reach menopause by the age of $52 .{ }^{29}$ It is well known that male pattern obesity (the so-called apple shape) and metabolic syndrome become more common in postmenopausal females. ${ }^{30}$ Our female participants gained more weight and had a significantly greater increase in BMI than males. Furthermore, we found that decline in FVC in obese females was higher than obese males. Male pattern obesity would be expected to cause greater diaphragmatic splinting and lung restriction than female pattern obesity (pear shape). New-onset asthma and respiratory symptoms increased in females not on exogenous hormonal therapy on becoming postmenopausal in a longitudinal population-based study in Northern Europe. ${ }^{31}$

Tobacco smoking is the major risk factor for the development of airflow limitation and COPD, ${ }^{11,32}$ and a previous study has suggested that smoking females are at greater risk than males. ${ }^{33}$ Possible mechanisms would include smaller airways, sex differences in smoke metabolism, immunologi$\mathrm{cal}$, or hormonal differences. ${ }^{33} \mathrm{We}$ found that female current smokers had higher mean $\triangle \mathrm{FEV}_{1}$ than male current smokers, but were unable to examine biological mechanisms. It is possible that our inability to detect a significant effect of current smoking in males was because they had smoked less on average and/or limited statistical power. However, our overall findings confirmed the importance of smoking cessation to preserve lung function. Cumulative pack-years smoked appeared more important than current smoking, perhaps due to survivor effects. Although the prevalence of smoking has fallen over the last 25 years in Australia, young females are now just as likely to be current smokers as young males. ${ }^{34}$ Our findings provide some additional evidence for targeted smoking cessation campaigns directed toward females. This would also help reduce exposures in utero and during early childhood. The effect of maternal smoking appeared greatest in adult males consistent with some previous studies. ${ }^{35}$

\section{Strengths and limitations}

The ECRHS has the strengths of following a standardized protocol with validated questionnaires and careful attention to the quality of lung function data. However, similar to all cohort studies, there has been substantial attrition over 20 years. While the original sample was population based, the remaining subjects might not be fully representative of middle-aged adults in Melbourne. Specifically, those who dropped out were slightly younger and perhaps surprisingly more likely to report respiratory symptoms. So, the prevalence of some symptoms 20 years later was likely to be underestimated. Unfortunately, different types of spirometers were used in each survey. The pneumotach used a differential pressure transducer, whereas the EasyOne has an ultrasonic flow transducer. We were unable to find a direct head-to-head comparison, but the choice of spirometer can affect the sample size required for clinical studies with endpoints such as $\mathrm{FEV}_{1}{ }^{36}$ This local analysis has limited statistical power, particularly to examine less common risk factors and exposures. The final pooled and cleaned lung function data from all centers are awaited, which will be the subject of a planned international analysis.

\section{Conclusion}

Obesity and smoking put females at higher risk of LFD than males. In Australia, there are already health promotion campaigns around healthy eating, physical activity, and smoking cessation. Our findings suggest that these could, in part, be retargeted toward females to reduce the future risk of chronic lung diseases. We would encourage clinicians to ask middleaged patients presenting with respiratory symptoms about early life factors, as well as taking a full smoking history and measuring their height, weight, and lung function.

\section{Acknowledgments}

The ECRHS in Australia was funded by the Asthma Foundation of Victoria, Allen + Hanburys and the National Health and Medical Research Council (NHMRC). Haydn Walters was an investigator in ECRHS I in Melbourne. We thank Joan Raven, Anna Lanigan, Paulette Theodoulis, Mahesh 
Dharmakumara, Christopher Stuart-Andrews, and Natalie Zajakovski for their assistance in testing participants.

\section{Disclosure}

Michael Abramson holds investigator initiated grants for unrelated research from Pfizer and Boehringer-Ingelheim. He has undertaken an unrelated consultancy for AstraZeneca. He has received assistance with conference travel from Boehringer-Ingelheim and Sanofi. The other authors report no conflicts of interest in this work.

\section{References}

1. Burney P, Chinn DJ, Luczynska C, Lai E. Variations in the prevalence of respiratory symptoms, self-reported asthma attacks, and use of asthma medication in the European Community Respiratory Health Survey. Eur Respir J. 1996;9:687-695.

2. Burney P, Malmberg E, Chinn S, Jarvis D, Luczynska C, Lai E. The distribution of total and specific serum IgE in the European Community Respiratory Health Survey. J Allergy Clin Immunol. 1997;99(3): 314-322.

3. Abramson M, Kutin JJ, Raven J, Lanigan A, Czarny D, Walters EH. Risk factors for asthma among young adults in Melbourne, Australia. Respirology. 1996;1(4):291-297.

4. de Marco R, Accordini S, Cerveri I, et al. Incidence of chronic obstructive pulmonary disease in a cohort of young adults according to the presence of chronic cough and phlegm. Am J Respir Crit Care Med. 2007; 175(1):32-39.

5. Karunanayake CP, Rennie DC, Pahwa P, Chen Y, Dosman JA. Predictors of respiratory symptoms in a rural Canadian population: A longitudinal study of respiratory health. Can Respir J. 2011;18(3):149-153.

6. James AL, Knuiman MW, Divitini ML, et al. Risk factors for respiratory symptoms in adults: the Busselton Health Study. Respirology. 2013;18(8):1256-1260.

7. Skorge TD, Eagan TM, Eide GE, Gulsvik A, Bakke PS. The adult incidence of asthma and respiratory symptoms by passive smoking in uterus or in childhood. Am J Respir Crit Care Med. 2005;172(1):61-66.

8. Jacquemin B, Siroux V, Sanchez M, et al. Ambient air pollution and adult asthma incidence in six European cohorts (ESCAPE). Environ Health Perspect. 2015;123(6):613-621.

9. Hankinson JL, Odencrantz JR, Fedan KB. Spirometric reference values from a sample of the general U.S. population. Am J Respir Crit Care Med. 1999;159(1):179-187.

10. Stanojevic S, Wade A, Stocks J, et al. Reference ranges for spirometry across all ages: a new approach. Am J Respir Crit Care Med. 2008; 177(3):253-260.

11. Fletcher C, Peto R, Tinker C, Speizer F. The Natural History of Chronic Bronchitis and Emphysema. Oxford: Oxford University Press; 1976: 78-85, Appendix B:163-223.

12. Wilken D, Velasco Garrido M, Manuwald U, Baur X. Lung function in asbestos-exposed workers, a systematic review and meta-analysis. J Occup Med Toxicol. 2011;6(1):21.

13. Portengen L, Hollander A, Doekes G, de Meer G, Heederik D. Lung function decline in laboratory animal workers: the role of sensitisation and exposure. Occup Environ Med. 2003;60(11):870-875.

14. Lange P, Parner J, Vestbo J, Schnohr P, Jensen G. A 15-year follow-up study of ventilatory function in adults with asthma. N Engl J Med. 1998; 339(17):1194-1200.

15. Tai A, Tran H, Roberts M, et al. Outcomes of childhood asthma to the age of 50 years. J Allergy Clin Immunol. 2014;133(6):1572-1578.
16. Frew AJ, Kennedy SM, Chan-Yeung M. Methacholine responsiveness, smoking, and atopy as risk factors for accelerated FEV1 decline in male working populations. Am Rev Respir Dis. 1992;146(4):878-883.

17. Burgess JA, Walters EH, Byrnes GB, et al. Childhood adiposity predicts adult-onset current asthma in females: a 25 -yr prospective study. Eur Respir J. 2007;29(4):668-675.

18. Watson L, Vonk JM, Lofdahl CG, et al. Predictors of lung function and its decline in mild to moderate COPD in association with gender: results from the Euroscop study. Respir Med. 2006;100(4):746-753.

19. Donaldson GC, Seemungal TAR, Patel IS, et al. Airway and systemic inflammation and decline in lung function in patients with COPD. Chest. 2005;128(4):1995-2004.

20. Zaigham S, Wollmer P, Engström G. Lung function, forced expiratory volume in $1 \mathrm{~s}$ decline and COPD hospitalisations over 44 years of follow-up. Eur Respir J. 2016;47(3):742-750.

21. Burney PG, Luczynska C, Chinn S, Jarvis D. The European Community Respiratory Health Survey. Eur Respir J. 1994;7(5):954-960.

22. Abramson M, Kutin J, Czarny D, Walters EH. The prevalence of asthma and respiratory symptoms among young adults: is it increasing in Australia? J Asthma. 1996;33(3):189-196.

23. Abramson MJ, Wlodarczyk JH, Hensley MJ, Saunders NA. Evaluation of a new asthma symptoms questionnaire. J Asthma. 1991;28:129-139.

24. Olivieri M, Poli A, Zuccaro P, et al. Tobacco smoke exposure and serum cotinine in a random sample of adults living in Verona, Italy. Arch Environ Health. 2002;57(4):355-359.

25. de Marco R, Marcon A, Jarvis D, et al. Prognostic factors of asthma severity: a 9-year international prospective cohort study. J Allergy Clin Immunol. 2006;117(6):1249-1256.

26. American Thoracic Society. Standardization of spirometry - 1987 update. Statement of the American Thoracic Society. Am Rev Respir Dis. 1987;136(5):1285-1298.

27. Miller MR, Hankinson J, Brusasco V, et al. Standardisation of spirometry. Eur Respir J. 2005;26:319-338.

28. Drummond MB, Hansel NN, Connett JE, Scanlon PD, Tashkin DP, Wise RA. Spirometric predictors of lung function decline and mortality in early chronic obstructive pulmonary disease. Am J Respir Crit Care Med. 2012;185(12):1301-1306.

29. Schoenaker DAJM, Jackson CA, Rowlands JV, Mishra GD. Socioeconomic position, lifestyle factors and age at natural menopause: a systematic review and meta-analyses of studies across six continents. Int J Epidemiol. 2014;43(5):1542-1562.

30. Carr MC. The emergence of the metabolic syndrome with menopause. J Clin Endocrinol Metab. 2003;88(6):2404-2411.

31. Triebner K, Johannessen A, Puggini L, et al. Menopause as a predictor of new-onset asthma: A longitudinal Northern European population study. J Allergy Clin Immunol. 2016;137(1):50-57.

32. Lundback B, Lindberg A, Lindstrom M, et al. Not 15 but $50 \%$ of smokers develop COPD? - Report from the obstructive lung disease in Northern Sweden studies. Respir Med. 2003;97(2):115-122.

33. Sorheim IC, Johannessen A, Gulsvik A, Bakke PS, Silverman EK, DeMeo DL. Gender differences in COPD: are women more susceptible to smoking effects than men? Thorax. 2010;65(6):480-485.

34. Germain D, Durkin S, Scollo M, Wakefield M. The long-term decline of adult tobacco use in Victoria: changes in smoking initiation and quitting over a quarter of a century of tobacco control. Aust N Z J Public Health. 2012;36(1):17-23.

35. Perret JL, Walters EH, Abramson MJ, McDonald CF, Dharmage SC. The independent and combined effects of lifetime smoke exposures and asthma as they relate to COPD. Expert Rev Respir Med. 2014; 8(4):503-514.

36. Jensen RL, Teeter JG, England RD, et al. Sources of long-term variability in measurements of lung function: implications for interpretation and clinical trial design. Chest. 2007;132(2):396-402. 
International Journal of COPD

\section{Publish your work in this journal}

The International Journal of COPD is an international, peer-reviewed journal of therapeutics and pharmacology focusing on concise rapid reporting of clinical studies and reviews in COPD. Special focus is given to the pathophysiological processes underlying the disease, intervention programs, patient focused education, and self management protocols.

This journal is indexed on PubMed Central, MedLine and CAS. The manuscript management system is completely online and includes a very quick and fair peer-review system, which is all easy to use. Visit http://www.dovepress.com/testimonials.php to read real quotes from published authors 